\title{
Socio-demographic patterns of tuberculosis patients, experience of a tertiary care medical college hospital of Bangladesh
}

\begin{abstract}
Pulmonary tuberculosis is an air born infectious disease caused by Mycobacterium tuberculosis and is a major cause of morbidity and mortality particularly in developing countries. There are 33 million cases of tuberculosis worldwide, 3 million annual death and 8 million persons developed active tuberculosis every year. If tuberculosis is detected early and fully treated, people with the disease quickly become non-infectious and are eventually cured. However multi-drug resistance tuberculosis, HIV associated tuberculosis and weak health system are the major challenges. An observational study was conducted over a period of one year from September 2015 to August 2016 in the Outpatient Department of Jahurul Islam Medical College Hospital and Department of Pathology, Jahurul Islam Medical College, Kishoregonj, Bangladesh. Most of the patients were in the age group of $15-34 y$ years (61.7\%). $69.6 \%$ of the patients belonged to lower income group. $50.9 \%$ patients had pulmonary tuberculosis, $43.7 \%$ patients had extra pulmonary tuberculosis and $5.4 \%$ had both pulmonary and extra pulmonary tuberculosis. The most common symptoms observed in pulmonary tuberculosis patients were cough with expectoration $(96.5 \%)$ followed by weight loss $(80.7 \%)$, fever $(73.7 \%)$ and loss of appetite $(54.4 \%)$ whereas in extrapulmonary tuberculosis patients majority had weight loss $(79.6 \%)$, fever $(67,3 \%)$, loss of appetite $(61.2 \%)$.
\end{abstract}

Keywords: tuberculosis, pulmonary tuberculosis, extra pulmonary tuberculosis
Volume 3 Issue 6 - 2016

\author{
AKM Maruf Raza,' Hafizur Rahman, ${ }^{2}$ \\ Mahfujun Nahar ${ }^{3}$ \\ 'Assistant Professor of Pathology, Jahurul Islam Medical College, \\ Bangladesh \\ ${ }^{2}$ Assistant Professor of Biochemistry, Jahurul Islam Medical \\ College, Bangladesh \\ ${ }_{3}^{3}$ ahurul Islam Medical College, Bangladesh
}

Correspondence: AKM Maruf Raza,Assistant Professor Department of Pathology, Jahurul Islam Medical College, Bajitpur, Kishoregonj, Bangladesh, Tel +880 I I I 306 I23, Email drmarufraza@gmail.com

Received: November 17, 2016 | Published: December 14, 2016

\section{Introduction}

Tuberculosis (TB) is one of the leading causes of mortality and morbidity among infectious diseases worldwide and has an enormous economic impact on many countries. ${ }^{1}$ Bangladesh is one of the highest TB burden countries accounting for one fifth of the global incidence of TB. ${ }^{2}$ The disease is more prevalent in the productive age group of 15-54yrs which causes an economic burden on the individual's household when they fall sick. The number of TB patients is increasing at a horrifying speed for several reasons. One is the lack of awareness of the disease, which makes patients neglect their symptoms till it is too late. For many they fear that they will surely die of TB and are therefore unable to accept the fact. Another very important reason for hiding the truth is the social stigma attached to TB. Women are thrown out of families, people lose their jobs and children are thrown out of school because of the irrational belief that TB is fatal and will kill all those who live in proximity to a TB patient. Once removed from the family, these people have a seriously diminished quality of life and die on the streets due to complications of the disease and starvation. Extra pulmonary TB occurs outside the lungs; in lymph nodes and in any organ system even brain and reproductive organs. The bacteria may spread through lymphatic or haematogenous dissemination. The TB bacteria may remain dormant for years at a particular site before causing the disease and may have a wide variety of clinical manifestations leading to difficulty and delay in its diagnosis. ${ }^{4}$

\section{Methods}

An observational study was conducted over a period of one year from September 2015 to August 2016 in the Outpatient Department of Jahurul Islam Medical College Hospital and Department of Pathology, Jahurul Islam Medical College, Kishoregonj, Bangladesh. A total of 112 patients, who came to outpatient department were interviewed. The inclusion criteria of the study were pulmonary and extra pulmonary tuberculosis cases diagnosed on the basis of sputum smear, culture, chest-radiograph, cytological and histopathological examination receiving antitubercular drugs therapy. Patients unwilling to participate in the study were excluded from the study. Informed consent was taken for the study. Patient's informed consent form including information regarding the study were provided to the patients for their understanding about the study and participation. Patient informed consent was written in Bengali language. Primary data from each patient was included in Tuberculosis Patient Profile form such as age, gender, educational level, annual income in taka, occupational status and selected social habits like smoking, alcohol.

\section{Results}

Out of 112 patients studied, 50(44.6\%) were male and 62(55.4\%) were female. The majority of patients $69(61.7 \%)$ were in the age group of 15-34years (Table 1). Annual family income of $78(69.6 \%)$ patients ranged between $36,000-1,50,000$ taka. In total 112 patients $43(38.4 \%)$ were illiterate and 36 patients $(32.2 \%)$ were unemployed. $50 \%$ of the patients were smoker. Among them $53.5 \%$ had pulmonary tuberculosis (Table 2). The most common sites involved in extrapulmonary tuberculosis were the lymph nodes $(38.2 \%)$ followed by the pleura $(36.4 \%)$. The most common symptoms observed in pulmonary tuberculosis patients were cough with expectoration 
(96.5\%) followed by weight loss (80.7\%), fever (73.7\%) and loss of appetite $(54.4 \%)$. Whereas in extrapulmonary tuberculosis patients majority had weight loss $(79.6 \%)$, fever $(67,3 \%)$, loss of appetite

$(61.2 \%)$. Both pulmonary and extrapulmonary patients had fever $(83.3 \%)$ and loss of appetite $(66.7 \%)$ as major clinical symptom (Table 3)

Table I Age and Gender distribution of the study subjects

\begin{tabular}{|c|c|c|c|c|c|c|}
\hline \multirow[b]{2}{*}{ Characteristics } & \multicolumn{4}{|c|}{ Number of patients } & \multirow[b]{2}{*}{$\begin{array}{l}\text { Total number of } \\
\text { patients }(\mathrm{N}=|| 2)\end{array}$} & \multirow[b]{2}{*}{ Percentage (\%) } \\
\hline & & $\begin{array}{l}\text { Pulmonary } \\
(\mathrm{N}=57)\end{array}$ & $\begin{array}{l}\text { Extra pulmonary } \\
(\mathrm{N}=49)\end{array}$ & $\begin{array}{l}\text { Pulmonary \& extra } \\
\text { pulmonary }(\mathrm{N}=6)\end{array}$ & & \\
\hline \multicolumn{7}{|l|}{ Gender } \\
\hline Male & 31 & & 16 & 3 & 50 & 44.6 \\
\hline Female & 26 & & 33 & 3 & 62 & 55.4 \\
\hline \multicolumn{7}{|c|}{ Age group (years) } \\
\hline I4-May & - & & 3 & 1 & 4 & 3.6 \\
\hline $15-24$ & 17 & & 16 & 1 & 34 & 30.4 \\
\hline $25-34$ & 14 & & 19 & 2 & 35 & 31.3 \\
\hline $35-44$ & 6 & & 5 & - & 11 & 9.8 \\
\hline $45-64$ & 16 & & 5 & 1 & 22 & 19.6 \\
\hline$>64$ & 4 & & I & 1 & 6 & 5.3 \\
\hline
\end{tabular}

Table 2 Socio-demography and other characteristics of tuberculosis patients

\begin{tabular}{llllll}
\hline \multirow{2}{*}{ Characteristics } & \multicolumn{2}{l}{ Number of patients } & Total number of & Percentage (\%) \\
\cline { 2 - 6 } & $\begin{array}{l}\text { Pulmonary } \\
(\mathrm{N}=57)\end{array}$ & $\begin{array}{l}\text { Extra pulmonary } \\
(\mathrm{N}=49)\end{array}$ & $\begin{array}{l}\text { Pulmonary \& extra } \\
\text { pulmonary }(\mathrm{N}=6)\end{array}$ & patients $(\mathrm{N}=\mathrm{I}$ I 2) & \\
\hline
\end{tabular}

\section{Employment Status}

$\begin{array}{llllll}\text { Employed } & 25 & 19 & 3 & 47 & 41.9 \\ \text { Unemployed } & 16 & 18 & 2 & 36 & 32.2 \\ \text { Retired } & 5 & 1 & - & 6 & 5.3 \\ \text { Student } & 11 & 11 & 1 & 23 & 20.6\end{array}$

Social habits

$\begin{array}{llllll}\text { Smokers } & 36 & 12 & 8 & 56 & 50 \\ \text { Alcoholic } & 3 & 2 & 1 & 6 & 5.3 \\ \text { Nonsmokers } & 20 & 28 & 2 & 50 & 44.6\end{array}$

Education

\begin{tabular}{|c|c|c|c|c|c|}
\hline None & 23 & 19 & I & 43 & 38.4 \\
\hline Primary & 16 & 13 & 2 & 31 & 27.7 \\
\hline High school & 10 & 7 & I & 18 & 16.1 \\
\hline University & 8 & 10 & 2 & 20 & 17.8 \\
\hline \multicolumn{6}{|c|}{ Annual family income (Taka) } \\
\hline $36,000-1,00,000$ & 21 & 18 & 4 & 39 & 34.8 \\
\hline I,0I,000- I,50,000 & 23 & 15 & I & 39 & 34.8 \\
\hline
\end{tabular}


Table 3 Clinical presentation of patients with pulmonary and extra pulmonary tuberculosis

\begin{tabular}{|c|c|c|c|}
\hline Characteristics & Pulmonary (\%) (N=57) & Extra pulmonary (\%) $(\mathrm{N}=49)$ & Pulmonary+ Extra pulmonary (\%) $(\mathrm{N}=6)$ \\
\hline Cough with Expectoration & $55[96.5 \%]$ & $20[40.8 \%]$ & $03[50 \%]$ \\
\hline Loss of Appetite & $3 \mathrm{I}[54.4 \%]$ & $30[61.2 \%]$ & $04[66.67 \%]$ \\
\hline Fever & $42[73.7 \%]$ & $33[67.3 \%]$ & $05[83.33 \%]$ \\
\hline Sweating & $19[33.3 \%]$ & $06[12.2 \%]$ & $0 \mathrm{I}[16.67 \%]$ \\
\hline Chills & $27[47.4 \%]$ & $22[44.9 \%]$ & $03[50 \%]$ \\
\hline Fatigue & $25[43.9 \%]$ & II [22.4\%] & $04[66.67 \%]$ \\
\hline Weight Loss & $24[42.1 \%]$ & I5[ 30.6\%] & $02[33.33 \%]$ \\
\hline Chest Pain & $04[7.0 \%]$ & I3[ 26.5\%] & - \\
\hline Abdominal Pain & 19 [33.3\%] & II [ $22.4 \%]$ & $03[50 \%]$ \\
\hline Breathlessness & $13[22.8 \%]$ & $19[38.8 \%]$ & $04[66.67 \%]$ \\
\hline Swelling & - & $16[32.7 \%]$ & - \\
\hline Body Ache & 13 [22.8\%] & I8[ 36.7\%] & $0 \mathrm{O}[16.67 \%]$ \\
\hline
\end{tabular}

\section{Discussion}

Pulmonary tuberculosis is an air born infectious disease caused by Mycobacterium tuberculosis and is a major cause of morbidity and mortality particularly in developing countries. In this study a total of 112 diagnosed TB patients undergoing treatment were studied. Of these $50(44.6 \%)$ were males and 62(55.4\%) were females, which suggests that the number of female patients are more compared to male patients which is similar to a study conducted by Gamil Qasem Othman et al. ${ }^{5}$ This could be because women often face some obstacles such as high female illiteracy, ill health with lower immune status, massive house hold work load and economic dependency that allow them limited access to health care. Of the 112 tuberculosis patients evaluated, $69(61.7 \%)$ patients were within the age group of 15-34years. This shows that TB mainly infects the productive age group constituting to a strong economic burden and affect their working potentiality. A large number of study populations were illiterate 43(38.4\%). As level of education is an important factor in with knowledge about disease, educational status of the community is one of the key factor for the success or failure of the treatment in tuberculosis. In the present study, $41.9 \%$ were employed. The educational level and employment status of this study was found consistent with the studies from Brazil conducted by Ricardo Steffen et al. ${ }^{6}$ Only $10(8.9 \%)$ of the patients had annual family income more than 2 lacks taka which shows tuberculosis affects middle class and lower class economic population group. Unemployment, lower Educational Level, unhealthy living environment and overcrowding living condition may be the reason for TB in lower socio economic class people. This study show 56(50\%) of the patients are smoker suggesting smoking is one of the main risk factor for TB. Furthermore, behavioral factors especially cigarette smoking and alcohol use have negative effect on TB treatment. Cigarette smoking is known to damage the lungs and suppress the individual adaptive immune responses affecting patient's response to TB treatment. In our study $50.9 \%$ patients had pulmonary tuberculosis, $43.7 \%$ patients had extra pulmonary tuberculosis and $5.4 \%$ were both pulmonary and extrapulmonary tuberculosis. Pulmonary tuberculosis were more common than extra pulmonary tuberculosis. This study also show pulmonary tuberculosis is more common in men $(54.4 \%)$ than in women $(45.6 \%)$. The same result was also observed in a study by Noertjojo et al. ${ }^{7}$ Recent studies have suggested that the sites of extra-pulmonary tuberculosis may vary according to geographic location and population. It is well known that lymph node and pleural involvement in TB is a direct extension of the disease from lung parenchyma. ${ }^{8}$ In this study the most common sites involved in extrapulmonary tuberculosis were the lymph nodes (38.2\%) followed by the pleura $(36.4 \%)$ which is consistent with the study from Nepal conducted by Chandrashekhar T Sreeramareddy et al. ${ }^{9}$ The signs and symptoms of pulmonary TB are typical and known (cough and sputum) whereas extra pulmonary TB is difficult to identify not only by the patients but also by the clinicians themselves. ${ }^{10}$ In this study $96.5 \%$ of patients of pulmonary TB and $40.8 \%$ patients of extrapulmonary TB has cough with expectoration which was also observed in similar study conducted by Gamil Qasem Othman et al. ${ }^{5}$

\section{Conclusion}

Our study concludes that majority of the tuberculosis patients are within the economically productive age group ranged between 15-34years. Females are the majority of the patients with extra pulmonary tuberculosis while pulmonary tuberculosis predominantly occurred in men. The most common sites of involvement was the lymph nodes followed by pleura, spine and genitourinary tract. Based on this results TB control programme might usefully target young and female populations for early diagnosis to decrease tuberculosis morbidity and mortality.

\section{Acknowledgements}

None.

\section{Conflict of interest}

The author declares no conflict of interest.

\section{References}

1. Anunnatsiri S, Chetchotisakd P, Wanke C. Factors associated with treatment outcomesin pulmonary tuberculosis in northeastern Thailand. Southeast Asian J Trop Med Public Health. 2005;36(2):324-330.

2. http://www.who.int/tb/publications/_global_report/gtbr14_executive summary.Pdf 
3. Shelly Batra. Improving the health care delivery through global collaboration. Operation ASHA-fighting Tuberculosis in India. 2008.

4. Gonzalez OY, Adams G, Teeter LD, et al. Extra-pulmonary manifestations in a large metropolitan area with a low incidence of tuberculosis. Int J Tuberc Lung Dis. 2003;7(12):1178-1185.

5. Gamil Qasem Othman, Mohamed Izham M Ibrahim, Yahia Ahmed Raja A. Comparison of the clinical and socio-demographical factors in pulmonary and extra pulmonary tuberculosis patients in Yemen. Journal of Clinical and Diagnostic Research. 2011;5(2):191-195.

6. Steffen R, Menzies D, Oxlade O, et al. Patients' costs and cost-effectiveness of tuberculosis treatment in DOTS and Non-DOTS Facilities in Rio de Janeiro, Brazil. PLoS One. 2010;5(11):e14014.

7. Noertjojo K, Tam CM, Chan SL, et al. Extra-pulmonary and pulmonary tuberculosis in Hong Kong. International Journal of Tuberculosis lung Disease. 2002;6(10):879-886.
8. Khazaei S, Roshanaei G, Saatchi M, et al. The epidemiological aspects of tuberculosis in Hamadan Province during 2005-11. Int J Health Policy Manag. 2014;2(2):75-80.

9. Chandrashekhar T Sreeramareddy, Kishore V Panduru, Sharat C Verma, et al. Comparison of pulmonary and extrapulmonary tuberculosis in Nepal- a hospital-based retrospective study. BMC Infectious Diseases. 2008;8:1-8.

10. Muniyandi M, Ramachandran R, Balasubramanian R, et al. Socioeconomic dimensions of tuberculosis control: review of studies over two decades from Tuberculosis Research Center. J Commun Dis. 2006;38(3):204-215. 